\section{Learning from Beirut: From Modernism to Contemporary Architecture}

\author{
Elie G. Haddad
}

\begin{abstract}
This paper will discuss the developments in architecture in Lebanon in the second half of the Twentieth century. Lebanon presents one of the interesting 'laboratories' of the different tendencies and movements of this past century, beginning with Modernism and its gradual assimilation, to Postmodernism and more current trends, in a context that presents a fertile field for experimentation. The questions of meaning, context, relations to place and tradition, have all played a part in the development of architecture in Lebanon, without necessarily achieving their desired goals, especially in the current climate of globalization. The loss of material identity that many regions around the world have experienced is reflected in the case of Lebanon, exacerbated here by political and social conflicts. This paper argues that the attempts to reinject material forms with a measure of 'communicative' symbols or forms fails in the end to answer to this perpetual desire for 'identity'.
\end{abstract}

\section{Modern Architecture in Lebanon}

Modern Architecture in Lebanon witnessed its defining moments in the period between 1950 and 1970 when political and economic conditions facilitated the growth of a new direction in architecture. While certain scholars have argued that this 'golden age' carried some impetus towards urban and social reform, it is not certain to what extent the first and second generation of architects in Lebanon had in mind a complete modernist agenda in which architecture would be called upon to play the role of a catalyst for social reforms. ${ }^{1}$ It is true however, that the efforts of the Lebanese State to forge a new identity for the new country, specifically during President Fuad Shehab's rule $[1958-64], 2$ an identity at once distinct and independent from French Colonial and Pan-Arab affiliations, may have found in the International Style a tool for the implementation of a desired modernity. The recruitment of major international figures like Oscar Niemeyer for pilot projects such as the Tripoli Fair, ${ }^{3}$ [Fig.1] as well as the ambitious building program of new public schools, hospitals and other institutional buildings were in a sense part of this strategy of political and urban development.

This 'golden period' of architecture in Lebanon [19501970] was shortly followed by the civil war [1975-1990], which led to large-scale population displacement, and resulted in the destruction of towns and villages, while suburban and mountainous regions witnessed an even more devastating urbanization. The 'corrective' lessons of Post-Modernism in relation to context, identity and tradition were unfortunately misinterpreted in Lebanon, and the Arab World in general, as a license for a free escape into historicism and kitsch. It is important to note here that the pre-war phase [1960-1975] witnessed the participation of many Lebanese architects in large scale building projects in the Arab Gulf region, where they played a major role in marking these contexts with a distinct Modernist aesthetic. The period that followed the war [1990-2005] witnessed a similar Lebanese involvement in the Gulf region, yet this time, many of the tendencies prevailing in that region came back to affect developments in Lebanon, in a sort of reverse osmosis.

The 1970's constituted a period of consolidation for modern architecture in Lebanon. Whereas the previous decade witnessed a gradual assimilation of modernist principles and techniques of construction, the 1970's saw the dissemination of the modernist language, with an emphasis on the use of fair-faced concrete, influenced by the later works of Le Corbusier, Niemeyer and others. The experiments of Le Corbusier with concrete, especially in his Unite d'Habitation [1952] opened new possibilities for regional variations that were eagerly taken up around the world. In Lebanon, this new tendency found great popularity as it appeared to answer functional, climatic and cultural specificities.

In this context, university complexes and large schools presented new opportunities, as they extended from the macro to the micro scale, addressing a major theme of Modernism, i.e. the relationship between urban planning and architecture. A design direction was set in the early 1970's with two major complexes which became seminal works in this category: the Mont La Salle College and the School of Engineers, both sited on hilltops overlooking Beirut. Mont La Salle [1969-72] [Fig.1] was a joint effort of three architects, Khalil Khoury, Raoul Verney and Gregoire Serof. This complex was designed as a series of clusters 


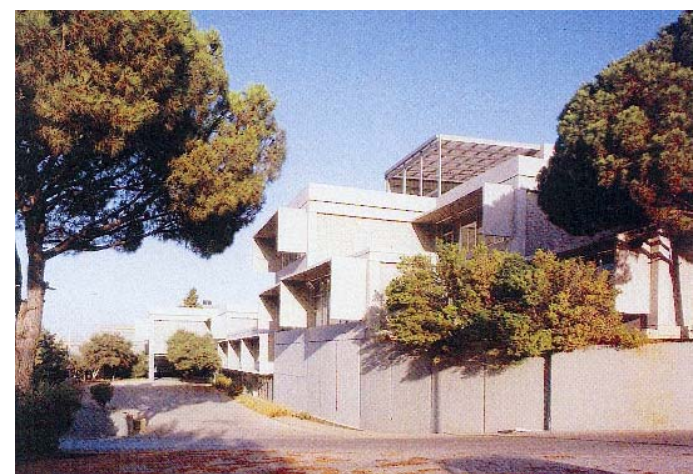

Figure 1: Mont La Salle

of repetitive units that constitute the modular classrooms, and sited naturally on a sloping terrain with a service road running at the back to separate between pedestrian and vehicular traffic. This arrangement allowed all classroom units to have different views, eliminating the traditional corridor-organized classrooms, giving the whole an organic character much in tune with 1960's experiments. The different units were all left in their 'natural' constructional finish, a concrete framework with concrete block infill, partly in answer to the economic requirements and partly for the interest in the new aesthetic opportunities of fair-faced concrete. Any notions of 'typology' or historic connotations of 'school' were obviously disregarded in this attempt to experiment with new forms of organization, at the expense of inherited 'meanings'. It is clear that at this stage, architecture stripped itself of its semantic dimension in favor of experimentations in syntax.

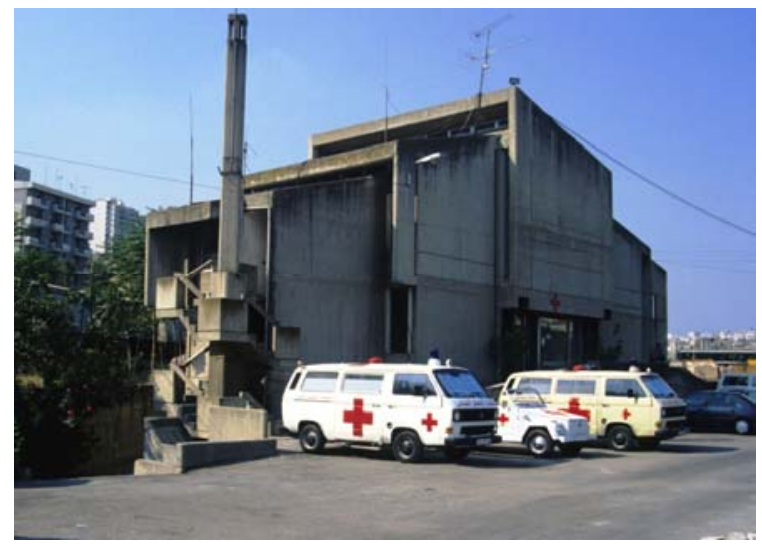

Figure 3: Red Cross Center

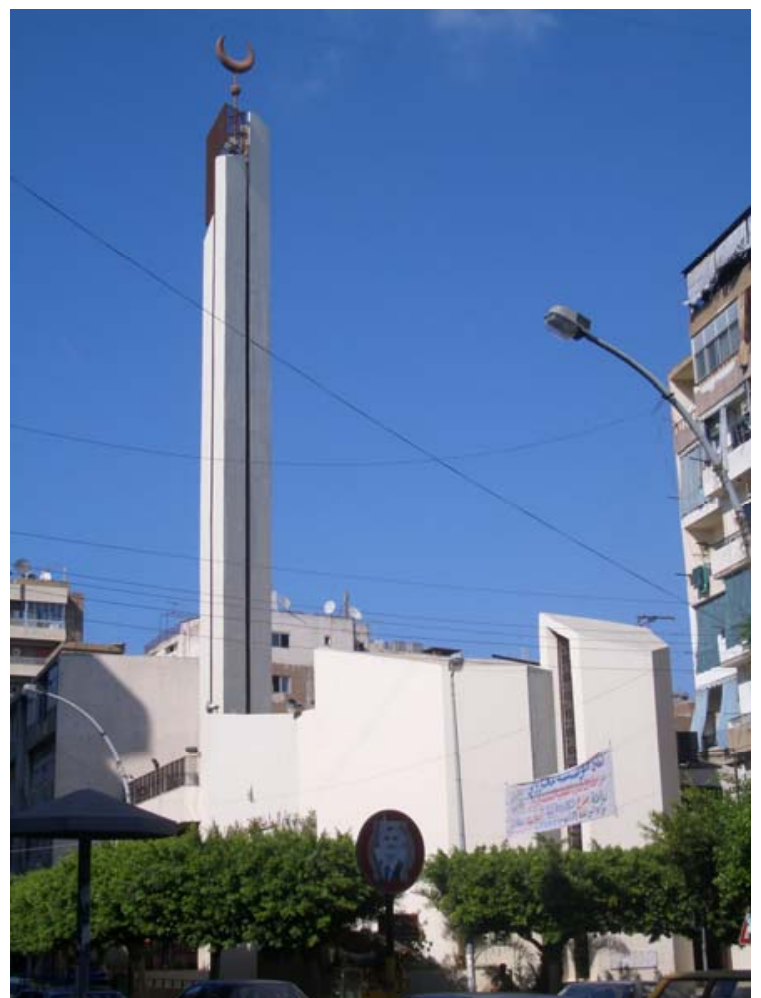

Figure 2: Mosque in Aicha Bakkar

Raoul Verney's Red Cross Center in Jounieh [1973] [Fig.2] presented another example of this tendency in architecture. The project shows a masterly resolution of a complex program consisting of an amphitheater, a social center, and a medical clinic, all packed in a compact structure on a tight parcel of land on the coastal highway. The design was partly dictated by site constraints, but also by the intention of the architect to organize the different components of the program in a structure that presents this multiplicity through the formal articulation of different volumetric elements. While the semantic component may be suppressed in the Mont La Salle college, this building may be read as playing on the semantic nuances of the chapel/religious institution, showing some affinities to another building of the same period, the Aicha Bakkar Mosque in Beirut.

At the same scale, the Mosque in Aicha Bakkar [1973] [Fig.3], designed by George Rayes and Jaafar Toukan, is an example of a sensitive insertion into a dense urban context, articulated around two main elements, one 
containing the entrance lobby, the other containing the double-height prayer hall. The geometric interplay of these two elements creates an intricate interior space, bathing in indirect lighting. The bare walls and neutrality of the surfaces emphasize the play of volumes, and the external appearance of the building displays similar articulations to the Red Cross project.

\section{Regionalist Tendencies in the 1970's}

Architects in the Arab world were not oblivious to the important developments that occurred in the 1950's-1970 period, a period that witnessed the maturation of Modern Architecture in the region. One can trace several examples of such 'responsive modernism' in the work of Assem Salam, Jacques Liger Belair, Raoul Verney, and Pierre el Khoury.

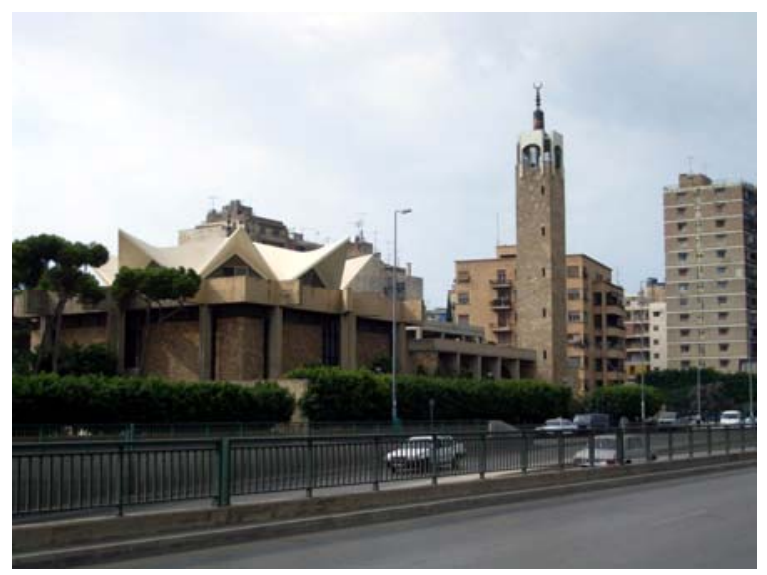

Figure 4: Kashoggi Mosque

Assem Salam can be credited with attempting to develop early on a synthesis of Modernism with local traditions, without lapsing into the postmodernist language of clichés. This appeared early on with his Saida Serail [1965] and continued in his Broumana High School Dorms [1966], culminating in the Kashoggi Mosque in Beirut [Fig.4] [1973], a building composed on a square plan within a rectangular space, where the articulation of elements bears some affinity to the work of Louis Kahn. The articulation of envelope and structure in the Kashoggi Mosque results in a distinctive building, with the enclosing walls made of local sandstone giving it a 'regional' accent without compromising its formal clarity and constructional logic. The minaret is reinterpreted here as a geometric 'campanile', with the application of an arch motif at the top of the tower, while the traditional dome is transformed into a pyramidal eight-pointed star. The Arabic star is thus translated into the cupola itself, a play on geometry characteristic of Islamic architecture more than the current trend of reviving outdated motifs. The mosque inadvertently assumes certain meanings as a religious building, and forces the visitor to compare it with its historical precedents. Here the linguistic analogy may be fruitful: the mosque appears as a text that borrows certain linguistic tropes from the history of its building type, yet reinterprets them in a distinctly modern form.

Another project in this line is the Chapel in Faqra by Raoul Verney [1983], a project which signaled a variation in the work of this architect [Fig.5]. The chapel drew on the traditional typology of the Mount-Lebanon churches, which were simple geometric cubes of stone masonry. The Faqra Chapel is a building of equal simplicity, based on a square plan and featuring stone-clad facades supported by a concrete structure. The interplay between these two materials is evident in the interior, where Verney introduced a diagonal axis of entry, subverting the traditional cross-shape plan. This diagonal axis is also expressed in the exterior which breaks at the altar end as well as the entrance to create an articulated corner condition. The side approach through a series of wide steps gives the chapel the role of a Propylea, framing its site.

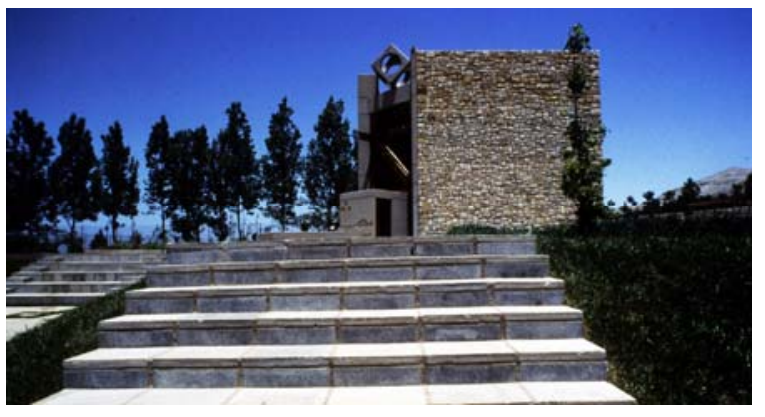

Figure 5: Chapel in Faqra

Villa Abou Kheir [1964] is an early masterpiece of the period by one of the pioneers of Modernism in Lebanon, Pierre El Khoury. The villa, perched on the coast overlooking a deep ravine, is discretely hidden from the road side behind a linear wall of rough fieldstone, which acts as the main datum of the house, enclosing the main service functions. The living area and dining space create an uninterrupted space which extends on the other side of the linear stone wall. A transversal wall that includes the 


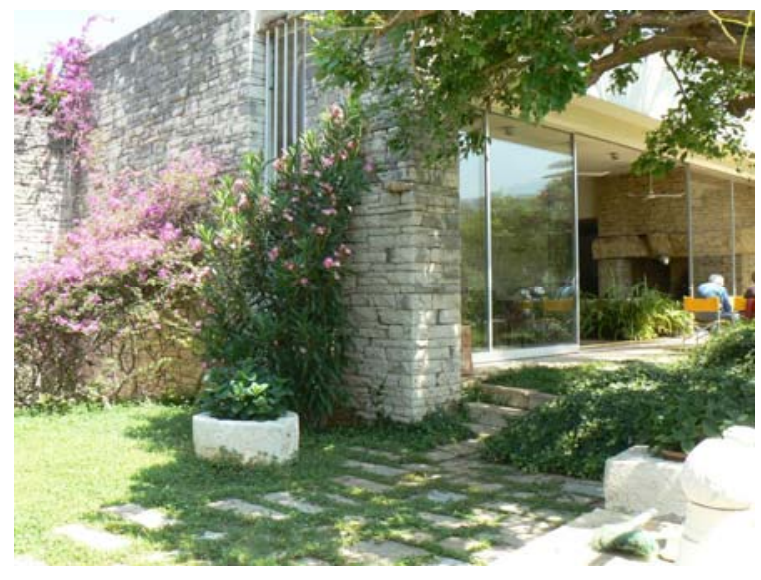

Figure 6: Villa Abou Kheir

large chimney marks the end of the living room, projecting to the exterior to blur the boundaries between inside and outside, house and nature. The projecting overhead canopy protects the interior from the harsh summer sun while allowing the winter sun to penetrate through. The mechanical systems are all integrated within the floor, while greenery invades the interior, creating a soft demarcation between living and dining areas. At the western extremity of the space, a stair leads down to one of the bedrooms, built into the rocks, and from there another stairway leads right down to the sea. More than anything, it is the integration of the house in its landscape which stands out, and shows a masterful resolution of the building program without any formal gymnastics.

\section{Pseudo Regionalism in Lebanon}

The confusion between regionalism and populism is quite evident in many projects where regionalism appears as a double-sided coin, on the one hand showing signs of a certain sensitivity to context and interest in 'semantics', while on the other proposing a superficial interpretation of culture. In discussing regionalism, one should thus be careful to distinguish between those projects that do not simply resort to imitation and clichés, and the more 'populist' variations which borrow simply the surface structure while failing to develop any creative synthesis.

This 'pseudo-regionalist' tendency in Lebanon appeared with a number of seaside resorts that broke with the Brutalist projects of the 70's and 80's. The Rimal complex by N. Farhat [1982] ushered a new direction in resort architecture, borrowing the aesthetic of Mediterranean villages in Spain. This was followed by the Portemilio complex by Zuber \& Saroufim, [1984-1996] [Fig.7] where

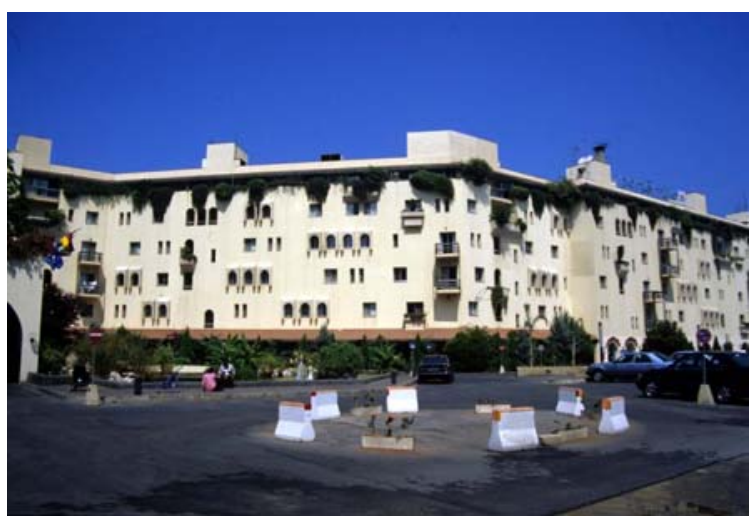

Figure 7: Portemilio complex

the arch motif is used to give a regional character to an otherwise bulky facade. After the war, this tendency took another impetus with a series of country clubs from theBeitMery Country Club by R. Baz [1993] to Batroun Village Club by Rayes \& Jamal, [2001], culminating with the complex of Faraya Mzaar by N. Khazen [2000].

New university campuses outside the urban centers also provided an opportunity for similar experiments in regionalism. The new campus of the Lebanese American University in Byblos by Samir Khairallah, [1985-] [Fig.8] is a case in point, providing one of the first models of this approach. The elementary architecture of the buildings based on the local vernacular projects a sense of harmony, articulated by the language of squares and streets that the Krier Brothers, Charles Moore and others had popularized in the 1980's.

This desire for the reaffirmation of 'identity' in the face of sometimes indiscriminate modernist impositions, even

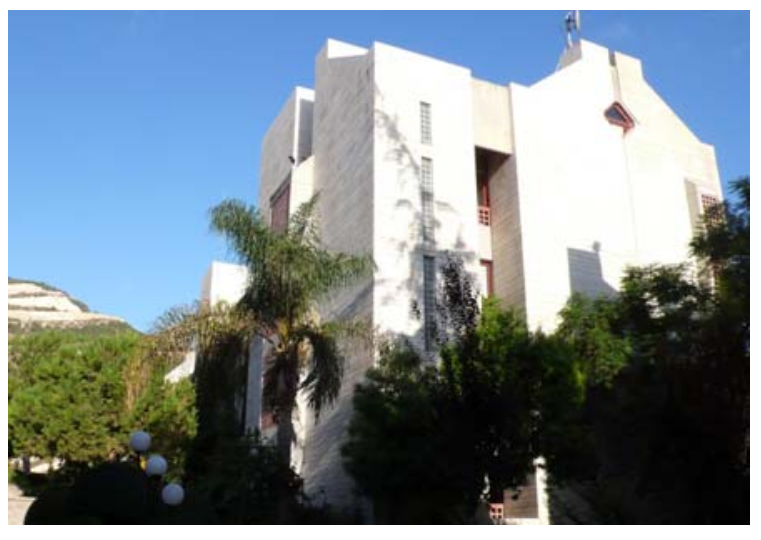

Figure 8: Lebanese American University 


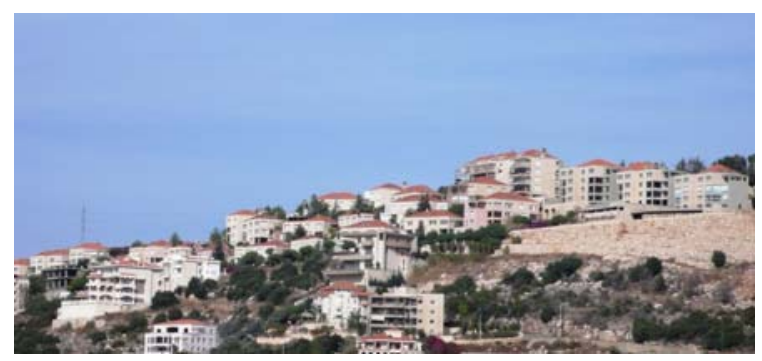

Figure 9: Bel Horizon complex

affected veteran modernists such as Pierre El-Khoury. Thus, on the hills of Adma, El-Khoury projected the Bel Horizon complex [1993] [Fig.9], a complex of low-rise villas that mimics the forms and organization of the historic villages of Mount Lebanon, with their quaint arrangement of rectangular houses covered by red-brick roofs. The relation between the architectural articulations and the social constitution of the new projects was of course never raised. Here, in complete ignorance of the original historic model, the new complex becomes a secluded enclave, closed to the general public and restricted to an elite group of homeowners.

An even more evident return to kitsch appeared with a number of projects that were subject to a disfiguring 'restoration'. In a counter-reaction to Modernism, modernist icons of the 1960's and 70's were covered with new façades of more 'regional' character. The transparency and structural clarity of the earlier architecture was replaced by opaque forms, signaling the return of a new monumentality laden with ornamental

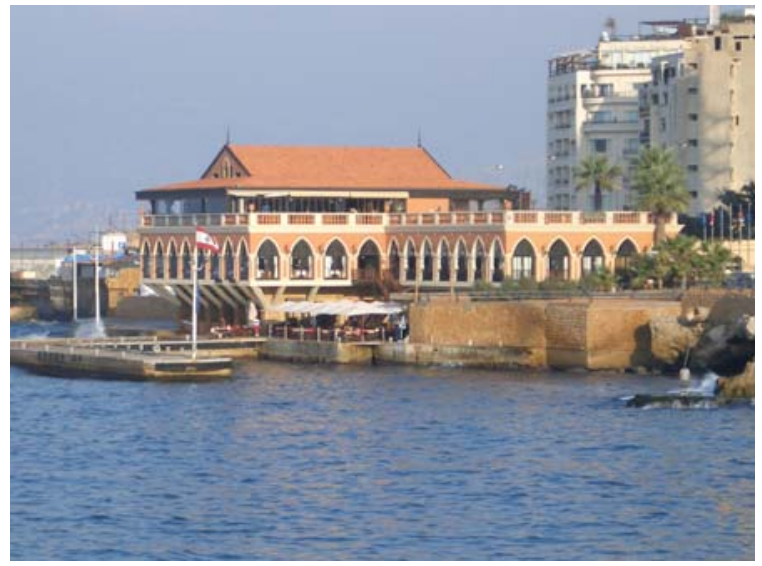

Figure 10: Artisan's House pastiche. The 'restoration' of the Presidential Palace by Pierre Neema [1992], the new residence of the Speaker of the House by Nabil Azar [1993], both major institutional projects of the New Republic after 1990, provided the keynote of this new direction in institutional taste, complemented by a similar tendency in the residence of the late Prime Minister Hariri [Oger Co., 1992].

The case of the Presidential Palace is particularly telling. Originally designed by the Swiss architects Addord \& Julliard in 1965 in an elegant modernist language, it was covered up after the war by a façade replicating the monumental architecture of Emirate period palaces [17$18^{\text {th }}$ centuries]. A similar disfiguration affected the Artisan's House in Ain el Mreisseh, turned into a kitschy restaurant after a complete make-up which covered up its elegant arcuated structure by a fake facade. [Fig.10]

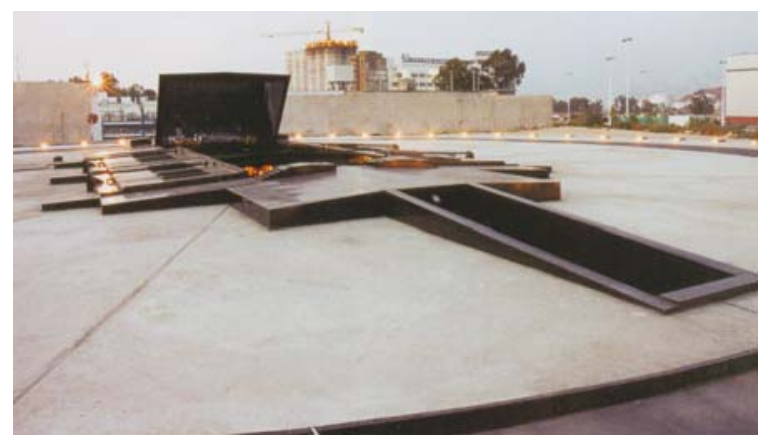

Figure 11: B-108 Nightclub

In parallel with this change in public taste, the degeneration resulted in a new brand of architectural projects made possible by the liberal translation of the post-modern license to create an eclectic architecture that appeals to popular taste. Thus, a hybrid form of regionalism emerged which began to constitute the majority of built works ravaging the country and the region, pretending to reconcile modernity and tradition by indiscriminately using elements from both repertoires.

\section{Contemporary Trends in Lebanese Architecture}

The development of contemporary architecture in Lebanon has been directly affected by the recent real estate boom which has led to mixed results. In most areas, 'hybrid' forms have chaotically invaded historic neighborhoods, violating their scale and urban continuity. In few cases, it has led to the emergence of significant projects, influenced 
by international trends yet attempting its own particular synthesis in this context.

The arrival of a new generation of young Lebanese architects in the 90's began to mark the new landscape in Lebanon as well as the landscape of other countries in the Middle East where they have been quite productive. The influence of Pop Art, Graphic Arts and Information Technologies on architecture has also affected the conceptual tools of these young architects, who are exploring an architecture that is both seductive and provocative, radical and contextual, imposing and discreet. This new architecture can also be characterized by its 'composite' character as opposed to the puritan character of the earlier modernist works; it is polychromatic as opposed to monochromatic, experimental rather than predetermined, 'morphic' as opposed to 'functionalist', and places an equal stress on the semantic as the syntactic.

Among this group of young architects, Bernard Khoury occupies a prime position. Some of his works have been published in international reviews and received international awards. Bernard Khoury rose to prominence with his B-018 Nightclub in the zone of Karantina [1998], a project which took the negative character of the place and its tragic history ${ }^{4}$ as a latent theme in the conceptualization of a project that buries itself in the ground, like a sarcophagus, and opens itself to the outside world only at night, through its mechanically operated roof. [Fig.11] It is interesting to note that, when asked about this project, Khoury would generally dismiss any overt symbolism or hidden meanings, pretending only to present an original solution in terms of structure and function, to a design problem. In other words, his projects are not designed to 'communicate' but simply to 'operate'.

Khoury moved on to design Centrale, a restaurant in a typical Nineteenth century house. Throwing against the wall all the traditions of restoration, Khoury rigged the place from within, emptying its hull and re-configuring its interior space. His projects all betray a certain tendency to confront reality in a form of shock-therapy, to provoke a reaction among the public by the 'difference' of the message communicated, often subliminally, while pretending to a certain ascetic withdrawal from its context. The firm of Nabil Gholam has been very prolific in Lebanon and abroad with distinctive projects. After modest beginnings with projects such as the National Shipping Company [1996], Gholam has realized major projects such

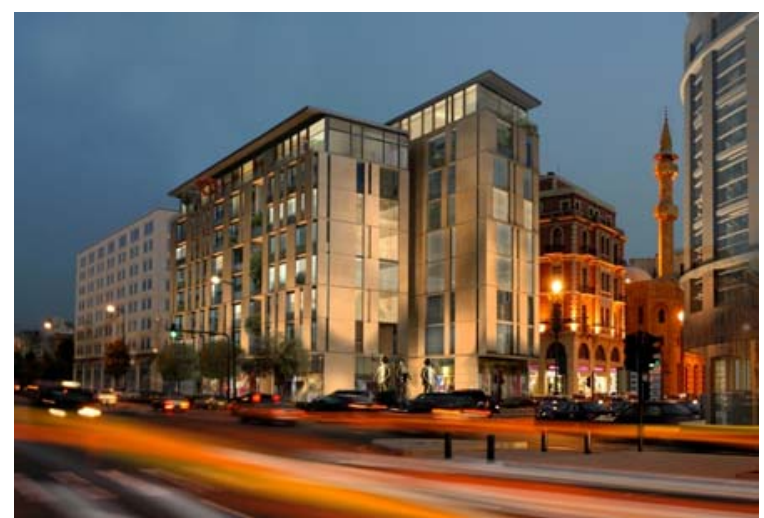

Figure 12: The Foch

as the 360 residential tower in Achrafieh [2005] and the Foch 94 [2004], a residential building where the façade is composed of alternating stone panels, creating a moderate interplay between opaque and transparent surfaces and allowing a variety of openings for the different residential units. [Fig.12] Gholam also won the competition to design the Engineering complex at the American University of Beirut, where he proposed a split-structure that responds morphologically to its site allowing major views and access routes to penetrate through the building complex, covered by a skin of moveable fins that adjust to different exposures.

Other emerging architects include Wissam Jabr, who designed the Dar-al-Aytam school complex in an environmentally conscious structure. In the field of residential houses, Jabr's Villa in Okaybeh [2004] ranks as a masterpiece of residential architecture.[Fig.13] The

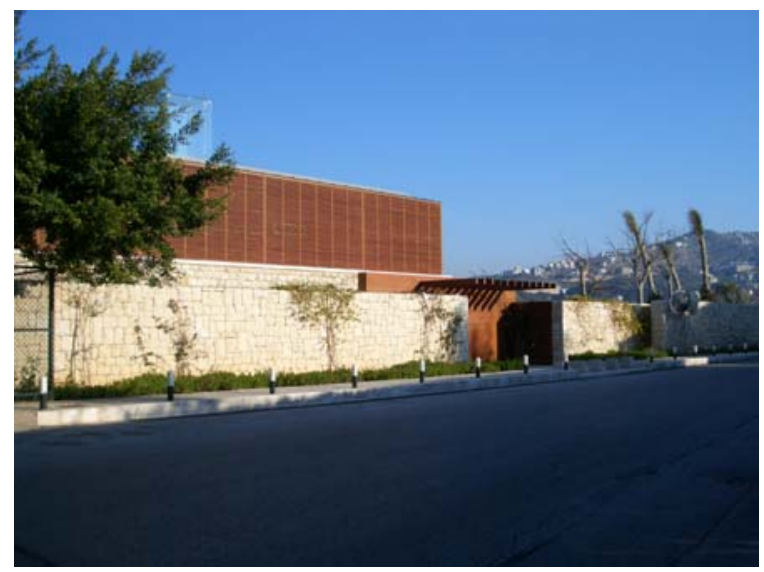

Figure 13: Jabr's Villa in Okaybeh 
house, designed on a site hanging over the rocky coastline, took an existing old house on the site as a template for the additional element that was added on top, with its transparent glass surfaces protected by a screen of wooden strips on the street side. The ground level of the existing house was redesigned to accommodate the basic public functions, with a transparent dining space that pierces through this envelope. In its formal asceticism, the house does not pretend to any overt symbolism, albeit in a subtle manner, through its play on materials, as opposed to relying on historicist elements.

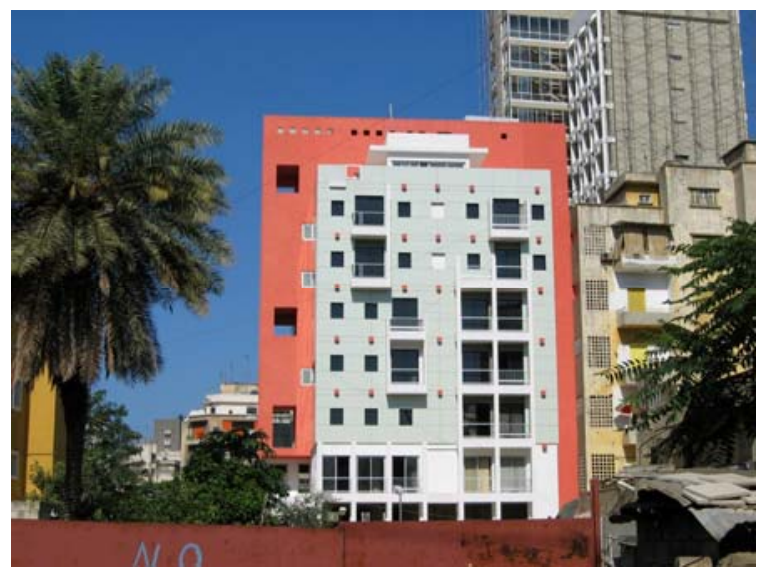

Figure 14: Risveglio office building

Other contemporary architects developed projects in a neo-rationalist tendency that draws on the legacy of the Venice School. Among those, Maroun Daccache pursued a typological search for an architecture that reinterprets the local traditions and inscribes itself within the morphology of the city. Among his recent works the Risveglio office building in Beirut [2005] attempts to address the typology of its neighborhood, yet its split organization appears like a break from the typology of the local Nineteenth century palazzo, and its polychromatic appearance clearly demarcates it from its context. [Fig.14] The interplay of elements presents a text of multiple codes that one attempts to decode by going to historical references from Terragni to Rossi.

Another 'neo-rationalist' approach can be seen in the work of Bawader architects, characterized by 'purist' forms and restrained articulations, as in the Lycee Abdel Kader School [Fig.15]. Here, spatial relations and the articulation

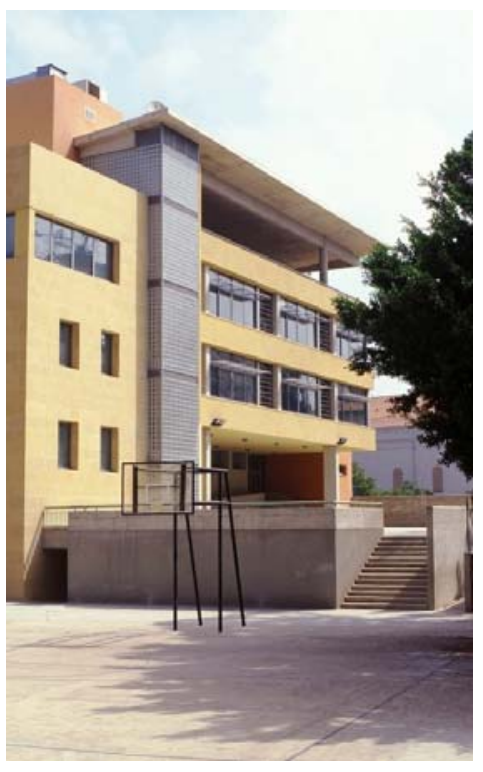

Figure 15: Lycee Abdel Kader School

of different elements provide a counterpoint to the historicist aesthetic.

The work of Hashim Sarkis distinguishes itself by attempting to follow the original agenda of Modernism. Sarkis continues through his engaged practice to believe in the capacity of architecture to positively transform society and adapt to its environment. Discrete and complex at the same time, his projects are socially engaged and environmentally sensitive. The Agricultural and Community Center in Mejdlaya [2004] [Fig.16] succeeds for instance in integrating a complex program of facilities in an agricultural zone, setting the different production and educational facilities on two levels, with an internal organization of courtyards that mediate between different spaces. His Pre-School \& Youth Center in Mejdlaya [project, 2001] is another example of the particular sensitivity to the landscape. Here, the architect proposed two low-lying structures to house the separate functions, integrated within the topography of the olive orchards, taking their cues from the geometry of the olive plantations. The resulting complex blends into the landscape, avoiding major disruptions to the land. This sensitivity is reflected in the plans which show the interrelation between outside and inside, between geometry and nature. Sarkis's approach throughout these projects betrays a deep understanding of historical 
references from Le Corbusier to Siza, as well as a keen attention to the functional requirements of each project, which allows for a personal interpretation that supersedes any inherited iconographies.

\section{Prospects and Challenges}

Architecture has always attempted to interact with the particularities of its time and place. If the current situation in Lebanon appears riddled by conflicting styles and tendencies and by a confusion of aesthetic directions, this is due in large part to the ambiguity of the existing sociopolitical situation, as well as the continuing search for a cultural identity, a search that is exacerbated by a 'globalization' that results in a proliferation of styles. As a result of this, architecture appears split among opposite poles, from a neo-avant-garde which seeks, for better or worse, to cater to the demands of a new 'society of the spectacle', sometimes producing forms that captivate the visual senses, to commercially-oriented practices which succumb to the speculative real-estate market, producing hybrids of different kinds. In between these extremes some architects attempt, with great difficulty, to create an architecture that responds equally to social and environmental challenges as well as to questions of context and cultural specificity.

The urban chaos in Beirut today is a direct result of this 'globalization'. An uncritical pluralism has been translated into a promiscuity of styles, now disseminated in schools of architecture. In the face of this, the lessons of the past could serve again as a last resource for a possible 'corrective' movement. These lessons include, in addition to the modernist masters, the lessons of contemporary architects in Switzerland, Spain and Portugal. The seminal examples of the 1960's in our own region should also be revisited, a period which has produced some masterpieces such as the Carlton, the Pan Am building, Hotel Alcazar, the Strand, Gondole; among many examples in Beirut alone. These buildings remain a living testimony to the capacity of architecture to provide the means for a sensible architecture that serves social needs without resorting to excess and a waste of materials and resources.

In retrospect, Modern Architecture, despite some of its major failures, presented a far richer language which, in its discretion, gave a refreshing alternative to the 'noisy' expressions of contemporary practice, from the slick to the
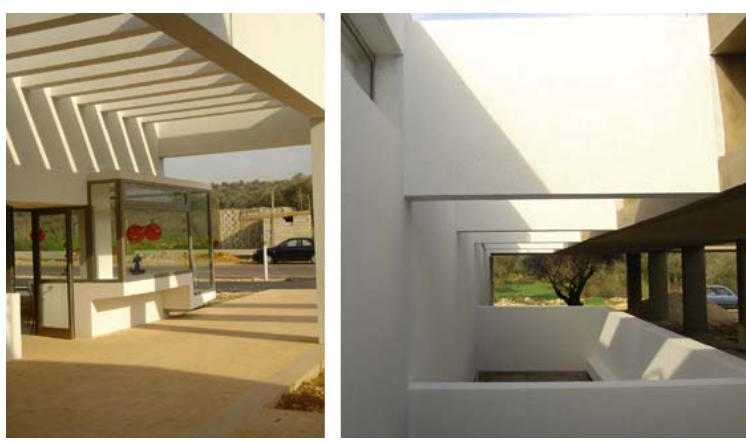

Figure 16: Agricultural and Community Center, Mejdlaya

kitschy. In the works of Mendelsohn, Aalto and Niemeyer, and at a local level in Lebanon, in the early works of Pierre Khoury, Verney and Salam; one finds a genuine attempt at integration, while later developments appear to have degenerated into a 'false consciousness' that pretends to resurrect 'culture' or 'meaning' in an economic mode that inevitably turns architecture into a mere commodity.

\section{Bibliography}

1 Jad Tabet, in a seminal article on this period, wrote that "Lebanese architects of the 50's and 60's were convinced that they were breaking new ground and that their search would lead them to discover new cultural territories. They shared a commitment to social improvement through design, and a feeling for the progressive potential of modern technology."

in "From Colonial Style to Regional Revivalism: Modern Architecture in Lebanon and the Problem of Cultural Identity" in Projecting Beirut, ed. By Peter Rowe and Hashim Sarkis, Prestel, 1998. [104]

Yet with the exception of his father, the architect Antoine Tabet, few architects had actually a record of pushing for social and urban reforms in parallel with their architectural activity.

Thus, in Beirut, and despite pressing social needs, the city never witnessed any social housing projects similar to what Bruno Taut or Ernst May had elaborated in Berlin and Frankfurt in the 1920's, or what other architects developed in Paris, Brussels, Rotterdam and other European cities throughout the Twentieth century.

2 Fouad Shehab, third president of the republic [1958-64], played a major role as founder of of many of the State's new institutions.

3 The Tripoli Fair project was commissioned to Niemeyer in 1963 during the Shehab regime, yet by the beginning of the Civil War in 1975, it was still incomplete. Current efforts to re-establish it as a center for exhibitions are faced by economic and political challenges.

4 The site of a Palestinian refugee camp overrun by the Christian militias in 1976. 